\title{
The Relationship Between Maternal Awareness, Socioeconomic Situation of Families and Metabolic Control in Children With Type 1 Diabetes Miletus in an Iranian Population
}

\author{
Fahimeh Soheilipour ${ }^{1}$; Atefeh Ghanbari Jolfaei ${ }^{1}$; Fariba Khodapanahandeh ${ }^{2}$; Asadollah \\ Rajab $^{3}$; Hamid Salehiniya ${ }^{4}$; Marjan Asoudegi ${ }^{2}$; Zeinab Tamannaie ${ }^{1}$; Nahid Rahimzadeh ${ }^{2, *}$ \\ ${ }_{2}^{1}$ Minimally Invasive Surgery Research Center, Iran University of Medical Sciences, Tehran, IR Iran \\ ${ }_{3}^{2}$ Pediatric Department, Iran University of Medical Sciences, Tehran, IR Iran \\ 3 Iranian Diabetes Society, Tehran, IR Iran \\ ${ }^{4}$ Department of Epidemiology and Biostatistics, School of Public Health, Tehran University of Medical Sciences, Tehran, IR Iran \\ ${ }^{*}$ Corresponding author: Nahid Rahimzadeh, Pediatric Department, Iran University of Medical Sciences, Tehran, IR Iran. Tel/Fax: +98-2166501113, E-mail: dr_rahimzadeh_ped@yahoo.com \\ Received: January 21, 2015; Revised: July 11, 2015; Accepted: July 20, 2015
}

Background: Type 1 diabetes mellitus (T1DM) is one of the most common chronic pediatric conditions, with potentially life-threatening sequels. However, good metabolic control can protect the patients against sequels.

Objectives: The aim of this study was to examine the relationship between awareness of the mothers about this disease on improving diabetic children metabolic control and also, to examine the relationship between socioeconomic situations of families and control of diabetes in this group of patients.

Patients and Methods: This is a cross-sectional descriptive analytic study on 80 diabetic children and their mothers, who were registered in the diabetes association of Iran, for outpatient control of disease. Diabetes knowledge was measured by Michigan diabetes knowledge test and glycemic control was assessed by glycosylated hemoglobin (HbA1c). To assess the socio-economic status of a diabetic child's family, educational level, occupational and marital status of parents were asked and the socioeconomic status (SES) was evaluated with Hollingshed four-factor index of SES.

Results: Mothers' mean knowledge score was 17.72, children's mean HbA1c was 7.77 and mean of SES was 27.89. There was no significant correlation between children's HbA1c and mother's SES. Also, there was an inverse linear relationship between mothers' knowledge score and children's HbAic and there was a direct linear relationship between the mothers' knowledge score and SES.

Conclusions: Finally, based on the results obtained in this study, it can be concluded that the awareness of mothers of T1DM children has a good impact on blood sugar control, whereas the SES of families has no direct effect on blood sugar control. Additionally, SES can indirectly impact on the consciousness of mothers and lead to the reduction of HbA1c.

Keywords: Awareness; Socioeconomic Status; Hemoglobin A, Glycosylated; Diabetes Mellitus; Type 1

\section{Background}

Type 1 diabetes mellitus (T1DM) is one of the most common endocrine and metabolic disorders in children and adolescents and the most common pediatric chronic condition worldwide (1). The incidence of T1DM is plainly on the increase, throughout the world and it is estimated that it may reach the status of a pandemic by the mid-21st century (2). The incidence of T1DM varies greatly between different countries, within countries, and between different ethnic populations (1). Because of the potentially life threatening sequels of uncontrolled T1DM, the optimal control of glucose level is very important for the diabetic children (1-4). Increases in diabetes prevalence and treatment costs have led to a growing number of studies for controlling this disease. Many of these studies have suggested that diabetic patients care requires changes in their lifestyle and one of the most effective methods for the treatment and control of diabetes is an effective change in patient's condition and lifestyle (5-8). Subsequently, self-care of diabetic patients and, also, changes in their life style require recognition and knowledge of patients about the principles of diabetic nutrition, monitoring of blood sugar levels and correct usage of insulin(9). Several studies have shown that there is a significant correlation between the higher awareness and improvement in glycemic control, in adult patients with diabetes mellitus (7). Parents' education and their active involvement in their child's

Copyright ( ) 2015, Iranian Society of Pediatrics. This is an open-access article distributed under the terms of the Creative Commons Attribution-NonCommercial 4.0 International License (http://creativecommons.org/licenses/by-nc/4.0/) which permits copy and redistribute the material just in noncommercial usages, provided the original work is properly cited. 
diabetes self-management are crucial tools to achieve the desired goals. In pediatric patients with T1DM, the primary caregiver is mostly the mother. Typically, self-management education and training for the mothers and their child begins with several sessions, during hospitalization, at the time of diagnosis (9).

\section{Objectives}

The aim of this study was to examine the relationship between awareness of the mothers about this disease, on improving diabetic children metabolic control and, also, to examine the relationship between socioeconomic status (SES) of families and the control of diabetes in this group of patients.

\section{Patients and Methods}

The present study is a cross-sectional descriptive analytic study on 80 diabetic children and their mothers, examining the relationship between metabolic control in children with T1DM and maternal knowledge and SES of the families. This study was performed by the diabetes association of Iran (DAI), in Tehran, from November 2010 to May 2011.

All persons attending this forum to make a membership in the DIA required passing a training course for 15 hours over 3 days, with participation of mothers and diabetic children.

This educational course included topics about the complications caused by diabetes, glycemic control, nutrition and exercise in diabetes management and the standard method for insulin injection. Then, every 3 months, metabolic control tests, including fasting blood sugar (FBS) and glycated hemoglobin (HbA1c) were required for all eligible participants. The results of these experiments were recorded in the offices to be analyzed.

The participants of this study included children who lived with their mothers and who were members of DAI. They were aged 5 - 15 years old.

Diabetes, in children who were enrolled in the study, should have a minimum duration of 1 year, and should have referred at least two times to the DAI last year.

For mothers of diabetic children, a written questionnaire was performed and was filled by non-random sampling (available method). Questionnaires had been distributed among them during the time they were waiting for physicians visit in the diabetes association.

Among the 80 mothers who participated, the questionnaire was distributed in 60 of them and in 57, questions were answered completely. The questionnaire had three parts; the first questions were asked to assess the knowledge of mothers, the second part was the demographic characteristics of mothers and children, and the third part was the assessment of socio-economic status of the families. To assess the knowledge of mothers of children with T1DM, we used the questionnaire: Michigan diabetes research and training center (MDRTC), with approved validity and reliability (9).

The questionnaire included 23 questions, 14 questions relating to the assessment of general information about diabetes and nine remaining questions were related to how to measure awareness of the mothers. Taking into consideration that there are several differences in diet in the Michigan study and the diet of people in Iran, we used several equivalents of diet in our questionnaire.

To assess the SES of a diabetic child's family, educational level, occupation and marital status of parents, the Hollingshed four-factor index of SES index was used (10).

To estimate the metabolic control of diabetic children, we used the average of HbA1c of each patient. The metabolic control status HbA1C level less than $7.5 \%$ was considered as optimal metabolic control and HbA1c above $9 \%$ represented poor control, while the averages between $7.5 \%$ - $9 \%$ represented medium control (11).

The levels of HbA1c were measured by high-performance liquid chromatography (HPLC) method and by a unique laboratory, and the instrument was D10 Bio-Rad (Bio-Rad Laboratories Inc., Hercules, CA, USA) (12). Given the normal distribution of mean, fast criterions were used to represent data

Because of normal distribution of variables, we used the mean and standard deviation for representing the data of study. Finally, for evaluating the relationship between maternal awareness, SES of families and HbA1c, the Spearman correlation coefficient was used.

The significance level was defined at a P value $<0.05$. The data analysis was performed by the SPSS software version 13 (SPSS Inc., Chicago, IL, USA).

\section{Results}

From a sample of 80,57 participants returned questionnaires (response rate: $71 \%)$. Of all children, 39 (68.4\%) children were male and 18 (31.9\%) were female. Mean age of children was $9.78 \pm 2.59$ years. On average, these children had developed diabetes at 6.62 years and the duration of diabetes was 3.16 years. Mothers' mean age was $36.9 \pm 4.92$.

Mothers' mean knowledge score was $17.72 \pm 2.6$ (11 - 23), children's mean HbA1c was 7.77 \pm 1.29 (5.4 - 12.9) and mean of SES was $27.89 \pm 13.16$ (7 - 61).

There was no significant correlation between children's age, mother's age, age at onset of diabetes, duration of diabetes and mothers' mean knowledge score, HbA1c and SES.

As one can see from Figure 1, there was an inverse linear relationship between mother's knowledge score and children's HbA1c $(P=0.007, r=0.352)$. Also, as evidenced in Figure 2, there was a direct linear relationship between the mothers' knowledge score and SES $(\mathrm{P}=0.002$, $r=0.401)$, while there was no significant correlation between HbA1c and SES (P > 0.05) (Table 1). 


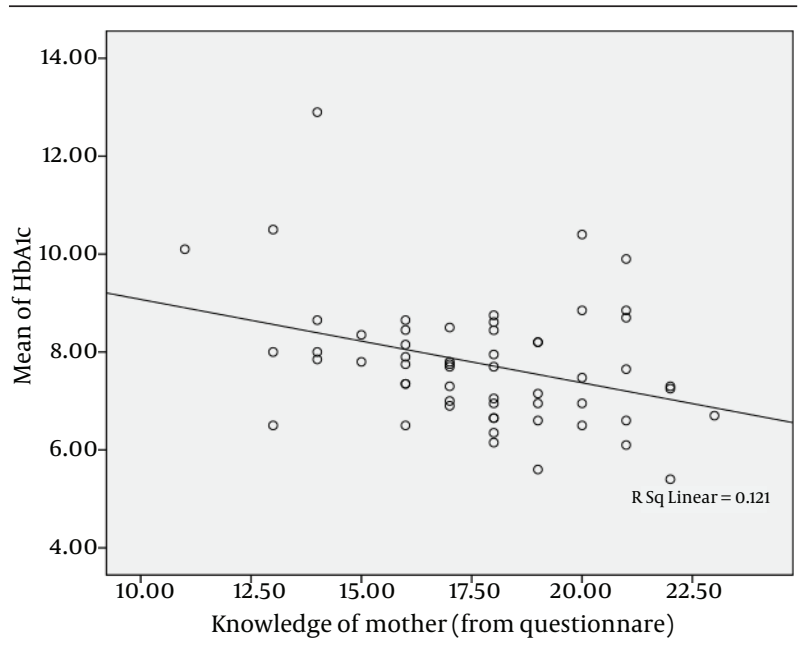

Figure 1. Scatter Plot of the Relationship Between Mother's Knowledge and Mean of Children's HbA1c

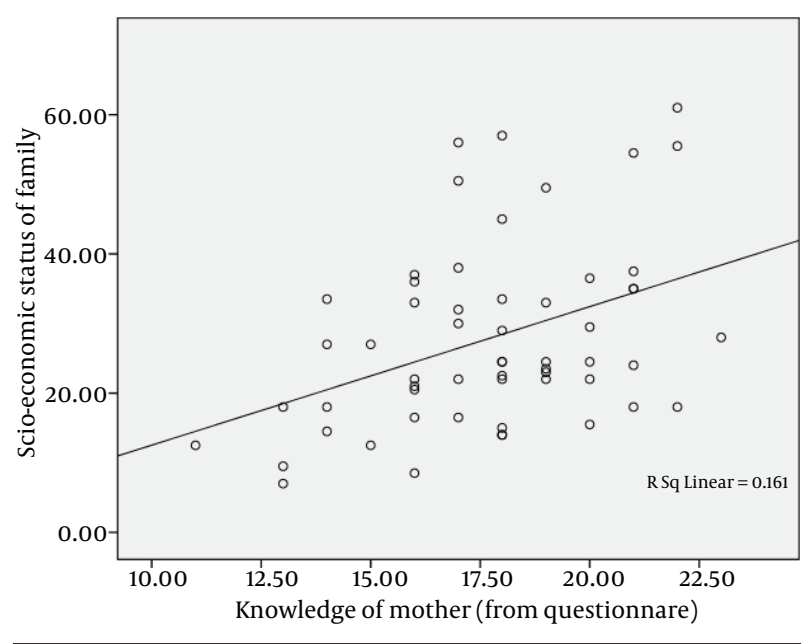

Figure 2. Scatter Plot of the Relationship Between Mother's Knowledge and Mean of Socio-Economic Status

Table 1. The Correlation Coefficient Between Mother's Knowledge and SES With $\mathrm{HbA1C}^{\mathrm{a}}$

\begin{tabular}{lcc}
\hline & Mother's Knowledge & SES \\
\hline Hba1c & 0.352 & 0.20 \\
$\mathbf{N}$ & 56 & 56 \\
Significance & 0.007 & 0.05 \\
\hline $\begin{array}{l}\text { a Abbreviations: HbA1c, glycated hemoglobin; and SES, socioeconomic } \\
\text { status. }\end{array}$
\end{tabular}

\section{Discussion}

The present study findings suggest that a higher awareness of mothers is correlated with better control of blood sugar in their children, in an Iranian population.

However, higher socioeconomic level of the families did not conducted to better control of blood glucose in the population of this study. Also, in this context, there existed a mutual communication between social and economic status of the family and knowledge about the children condition and disease, which explains the indirect relationship between the SES and the metabolic control of the child.

However, Tahirovic and Toromanovic (10) study demonstrated that the awareness level of diabetic children's mothers, who are their main care givers, has an effective role on blood sugar control. Mothers with more knowledge have children with better metabolic control, and low SES is significantly associated with higher levels of HbA1c. Nevertheless, in our study, there was a different result on the subject of SES.

Rezai et al. (13), in their study, observed that increased awareness, by educating adult individuals about diabetes, can lead to a better control in blood sugar in these patients.

Butler et al. (14), in 2008, depicted that a higher level of awareness among caregivers of individuals with diabetes causes significantly better glycemic control in the group of patients and this study concluded that for optimal glycemic control, treatment programs for youth with T1DM should include ongoing efforts to reinforce parental knowledge of diabetes, promote positive youth affect related to diabetes management, and acknowledge and reduce parental-perceived burden of diabetes management.

Our study is in line with these obtained findings. Furthermore, Stallwood (15), in 2006, showed that higher caregiver knowledge is associated with lower HbA1c levels. However, in our study, this applies to the maternal knowledge, especially.

Because most mothers are the main individuals who are in touch with diabetic children and also the most responsive people for taking care of diabetic patients in Iranian families, medical staff, including nurses, doctors and nutritionists should make a positive view about the necessity of giving information to and educating mothers of diabetic children, which can be performed during the times of regular visits or in ordinary intervals, as well as group training sessions for groups of mothers to be trained $(15,16)$.

In addition, better control of blood sugar, which may result from this methods of education, can decrease financial terms imposed on families (17).

Although a group of studies, such as Chaturvedi et al. (18), Tahirovic and Toromanovic (10) and Hassan et al. (19) have shown that a better level of SES can cause a better metabolic control, this result was not found in our study, which could be caused by a smaller sample size, different social and economic characteristics of our population, in comparison with other studies, and any confounding factors not mentioned in this study. However, other studies with a different sample size and population, including Dorchy et al. (20) study and Tubiana-Rufi et al. (21), dem- 
onstrated the same result of our study concerning the role of SES on blood glucose control.

Finally, based on the results obtained in this study, it can be concluded that the awareness level of mothers of diabetic children has a direct impact on blood sugar control of these patients. Also, the family's SES does not have a significant role on glycemic control of the children, although it can indirectly affect the level of awareness of mothers, thereby indirectly affecting metabolic control too.

Finally, training sessions to increase awareness of diabetes in mothers should be held regularly and routinely, for a better control of T1DM.

Additionally, review articles and studies, with greater sample sizes and concerning other factors of diabetic children glycemic control, should be undertaken.

\section{Acknowledgements}

We would like to appreciate S. Mokhber, Pishgah, Abdolreza Pazouki and Diabetes Association of Iran, for their kind cooperation.

\section{Authors' Contributions}

Asadollah Rajab and Marjan Asoudegi researched data, Fahimeh Soheilipour and Zeinab Tamannaie wrote the manuscript and Atefeh Ghanbari Jolfaei contributed to the discussion and reviewed the manuscript.

\section{References}

1. Faulkner MS, Chang LI. Family influence on self-care, quality of life, and metabolic control in school-age children and adolescents with type 1 diabetes. J Pediatr Nurs. 2007;22(1):59-68.

2. Silink M. Childhood diabetes: a global perspective. Horm Res 2002;57 Suppl 1:1-5.

3. McPherson ML, Smith SW, Powers A, Zuckerman IH, Association between diabetes patients' knowledge about medications and their blood glucose control. Res Social Adm Pharm. 2008;4(1):37-45.

4. Hassan K, Heptulla RA. Glycemic control in pediatric type 1 diabetes: role of caregiver literacy. Pediatrics. 2010;125(5):e1104-8.

5. Perry TL, Mann JI, Lewis-Barned NJ, Duncan AW, Waldron MA Thompson C. Lifestyle intervention in people with insulin-dependent diabetes mellitus (IDDM). Eur J Clin Nutr. 1997;51(11):757-63.
6. Hill-Briggs F, Lazo M, Peyrot M, Doswell A, Chang YT, Hill MN, et al. Effect of problem-solving-based diabetes self-management training on diabetes control in a low income patient sample. Gen Intern Med. 2011;26(9):972-8.

7. Delamater AM, Bubb J, Davis SG, Smith JA, Schmidt L, White $\mathrm{NH}$, et al. Randomized prospective study of self-management training with newly diagnosed diabetic children. Diabetes Care. 1990;13(5):492-8.

8. Bate KL, Jerums G. 3: Preventing complications of diabetes. Med J Aust. 2003;179(9):498-503.

9. Jiang YD, Chuang LM, Wu HP, Shiau SJ, Wang CH, Lee YJ, et al. Assessment of the function and effect of diabetes education programs in Taiwan. Diabetes Res Clin Pract. 1999;46(2):177-82.

10. Tahirovic H, Toromanovic A. Glycemic control in diabetic children: role of mother's knowledge and socioeconomic status. Eur JPediatr. 2010;169(8):961-4.

11. Fitzgerald JT, Funnell MM, Hess GE, Barr PA, Anderson RM, Hiss RG, et al. The reliability and validity of a brief diabetes knowledge test. Diabetes Care. 1998;21(5):706-10.

12. Rewers M, Pihoker C, Donaghue K, Hanas R, Swift P, Klingensmith GJ, et al. Assessment and monitoring of glycemic control in children and adolescents with diabetes. Pediatr Diabetes 2007;8(6):408-18.

13. Rezai N, Taherbaz F, Kimiagar M. Effect of educating nutrition on awareness and function of diabetic patients in Aligudarz city [in Persian].J Shahrekord Univ Med Sci. 2..6;8(2):52-9.

14. Butler DA, Zuehlke JB, Tovar A, Volkening LK, Anderson BJ, Laffel LM. The impact of modifiable family factors on glycemic control among youth with type 1 diabetes. Pediatr Diabetes. 2008;9(4 Pt 2):373-81.

15. Stallwood L. Relationship between caregiver knowledge and socioeconomic factors on glycemic outcomes of young children with diabetes. J Spec Pediatr Nurs. 2006;11(3):158-65.

16. Kovacs M, Finkelstein R, Feinberg TL, Crouse-Novak M, Paulauskas S, Pollock M. Initial psychologic responses of parents to the diagnosis of insulin-dependent diabetes mellitus in their children. Diabetes Care. 1985;8(6):568-75.

17. Panja S, Starr B, Colleran KM. Patient knowledge improves glycemic control: is it time to go back to the classroom? J Investig Med. 2005;53(5):264-6.

18. Chaturvedi N, Stephenson JM, Fuller JH. The relationship between socioeconomic status and diabetes control and complications in the EURODIAB IDDM Complications Study. Diabetes Care. 1996;19(5):423-30.

19. Hassan K, Loar R, Anderson BJ, Heptulla RA. The role of socioeconomic status, depression, quality of life, and glycemic control in type 1 diabetes mellitus.J Pediatr. 2006;149(4):526-31.

20. Dorchy H, Roggemans MP, Willems D. Glycated hemoglobin and related factors in diabetic children and adolescents under 18 years of age: a Belgian experience. Diabetes Care. 1997;20(1):2-6.

21. Tubiana-Rufi N, Moret L, Czernichow P, Chwalow J. Risk factors for poor glycemic control in diabetic children in France. Diabetes Care. 1995;18(11):1479-82. 